\title{
STUDI E-LEARNING BERBASIS KNOWLEDGE MANAGEMENT LINGKUNGAN HIDUP
}

\author{
Prasetya Cahya Saputra; Wahyu Sardjono; Tri Pudjadi \\ Information Systems Department, School of Information Systems, Binus University \\ Jl. K.H. Syahdan No. 9, Palmerah, Jakarta Barat 11480 \\ prasetyacs@gmail.com; wahyu.s@garuda-indonesia.com; wahyu.s@binus.ac.id
}

\begin{abstract}
National sustainable development needs to take into account the utilization of environmental natural resources for future generations. For the community, environment is a space or a place to stay for that need to be more preserved than utilized. Collaboration between knowledge of environment and preservation with ICT knowledge can be developed into a management system which is environmental knowledge management systems. Approach on the efficiency and effectiveness of ICT, which include variable timing, capacity, relevance, accessibility, flexibility, accuracy and reliability, can be used to explore the success determinants of communitybased environmental conservation as a central participant. Analysis method of this study uses the Core Process of KM consisting knowledge identification, knowledge aqcuition, knowledge development, knowledge sharing and distribution, knowledge utilization, and knowledge retention. Menawhile, the design method uses objectoriented based approach (OOAD) that contains the UML diagrams, followed by evaluation and verification of test results of the e-learning application prototype which will be measured by IT Balanced Scorecard through four perspectives, namely: (1) government contribution; (2) society orientation, (3) excellent operation, (4) future orientation. With the formulation of the critical success factors is then developed a virtual learning model, in order to raise public awareness of the importance of environmental preservation. The result is a prototype model of environmental KMS application or e-learning which will be piloted in a few areas, especially in Jabodetabek.
\end{abstract}

Keywords: e-learning, knowledge management, environment, conservation

\begin{abstract}
ABSTRAK
Pembangunan nasional berkelanjutan perlu memperhitungkan pendayagunaan sumberdaya alam yang berwawasan lingkungan untuk kebutuhan generasi mendatang. Bagi masyarakat, lingkungan hidup adalah merupakan ruang atau tempat tinggal bagi kehidupan sehingga perlu dilestarikan selain didayagunakan. Kolaborasi antara pengetahuan lingkungan dan pelestariannya dengan pengetahuan ICT dapat dikembangkan menjadi sebuah sistem pengelolaan, pengetahuan tentang lingkungan Environmental Knowledge Management Systems. Pendekatan efisiensi dan efektivitas pada ICT, yang meliputi variable ketepatan waktu, kapasitas, relevansi, aksesabilitas, fleksibilitas, akurasi dan realibilitas, dapat dipakai untuk mengeksplorasi faktor-faktor penentu keberhasilan pelestarian lingkungan hidup berbasis masyarakat sebagai sentra partisipan. Metode analisis menggunakan Core Process of KM yang terdiri knowledge identification, knowledge aqcuition, knowledge development, knowledge sharing and distribution, knowledge utilization, dan knowledge retention. Sedangkan metode perancangan adalah pendekatan berbasis objek (OOAD) yang berisi diagram-diagram UML, dilanjutkan dengan evaluasi dan verifikasi hasil uji coba prototype aplikasi e-learning akan dilakukan pengukuran dengan menggunakan IT Balanced Scorecard melalui 4 perspektif, yaitu: (1) government contribution; (2) society orientation; (3) operation excellent; (4) future orientation. Dengan dirumuskannya faktor penentu keberhasilan tersebut selanjutnya dikembangkan model pembelajaran maya, guna meningkatkan pemahaman masyarakat terhadap pentingnya pelestarian lingkungan. Hasilnya sebuah model prototipe aplikasi-environmental KMS atau e-learning yang akan diujicoba pada beberapa wilayah masyarakat khususnya di sekitar Jabodetabek.
\end{abstract}

Kata kunci: e-learning, knowledge management, lingkungan hidup, pelestarian 


\section{PENDAHULUAN}

Lingkungan Hidup adalah kesatuan ruang dengan semua benda, daya, keadaan, dan makhluk hidup termasuk manusia dan perilakunya yang mempengaruhi kelangsungan prikehidupan dan kesejahteraan manusia serta makhluk hidup lainnya (Amron, 2007). Pengelolaan Lingkungan Hidup adalah upaya terpadu untuk melestarikan fungsi lingkungan hidup yang meliputi kebijaksanaan penataan, pemanfaatan, pengembangan, pemeliharaan, pemulihan, pengawasan dan pengendalian lingkungan hidup

Lingkungan hidup menjadi bagian yang tak terpisahkan dari dinamika kehidupan masyarakat dan selalu terkait dengan kegiatan pembangunan yang telah, sedang dan akan dilaksanakan. Isu-isu lingkungan hidup menjadi semakin santer dewasa ini baik ditingkat lokal, regional, maupun nasional seperti pencemaran sungai, polusi udara, kerusakan lautan, terumbu karang dan sumber daya lainnya. Menurut Undang Undang No. 23 Tahun 1997, lingkungan hidup adalah kesatuan ruang dengan semua benda, daya, keadaan, dan makhluk hidup, termasuk manusia dan perilakunya, yang mempengaruhi kelangsungan perikehidupan dan kesejahteraan manusia serta makhluk hidup lain. Sedangkan ruang lingkup lingkungan hidup Indonesia meliputi ruang, tempat Negara Kesatuan Republik Indonesia yang berwawasan nusantara dalam melaksanakan kedaulatan, hak berdaulat, dan yurisdiksinya.

Dalam lingkungan hidup terdapat ekosistem, yaitu tatanan unsur lingkungan hidup yang merupakan kesatuan utuh menyeluruh dan saling mempengaruhi dalam membentuk keseimbangan, stabilitas, dan produktivitas lingkungan hidup. Dengan demikian lingkungan hidup Indonesia tidak lain merupakan Wawasan Nusantara, yang menempati posisi silang antara dua benua dan dua samudera dengan iklim tropis dan cuaca serta musim yang memberikan kondisi alamiah dan kedudukan dengan peranan strategis yang tinggi nilainya, tempat bangsa Indonesia menyelenggarakan kehidupan bernegara dalam segala aspeknya. Secara hukum maka wawasan dalam menyelenggarakan penegakan hukum pengelolaan lingkungan hidup di Indonesia adalah wawasan nusantara.

Lingkungan hidup dapat didefinisikan sebagai: (1) daerah di mana sesuatu mahluk hidup berada; (2) keadaan/kondisi yang melingkupi suatu mahluk hidup; (3) keseluruhan keadaan yang meliputi sekumpulan mahluk hidup, terutama: (a) kombinasi berbagai kondisi fisik di luar mahluk hidup yang mempengaruhi pertumbuhan, perkembangan dan kemampuan mahluk hidup untuk bertahan hidup; (b) gabungan dari kondisi sosial and budaya yang berpengaruh pada keadaan individu atau komunitas mahluk hidup.

Perhatian terhadap langkah-langkah pengembangan pendidikan lingkungan hidup pada beberapa tahun terakhir ini semakin meningkat, baik untuk pendidikan sekolah dan pendidikan luar sekolah, namun harus diakui bahwa masih banyak hal yang perlu terus diperbaiki agar pendidikan lingkungan hidup dapat lebih memasyarakat secara konsisten dan berkelanjutan. Dengan demikian, kegiatan sosialisasi lingkungan hidup yang dilaksanakan melalui berbagai bentuk kegiatan dapat memberikan hasil yang optimal. Semakin berkembangnya penggunaan teknologi informasi, menjadi peluang untuk penyebaran atau penyampaian perkembangan lingkungan hidup yang lebih cepat dan lebih baik. Di antara model penyampaian tersebut adalah melalui wahana internet, dengan mengembangkan model pembelajaran e-learning.

Melalui e-learning content yang berisi perkembangan mutakhir tentang lingkungan hidup dapat ditampilkan dengan menarik, pengguna(visitor) dapat ikut aktif melalui forum diskusi yang disediakan sehingga kualitas materi lingkungan hidup yang disampaikan semakin hari semakin berkembang. 


\section{METODE}

Tahap pertama dalam merancang model e-learning ini, diawali dengan melakukan analisis kebutuhan sosialisai pelestarian lingkungan hidup dan prioritasnya pada lembaga terkait, selanjutnya melakukan identifikasi masalah yang ada dan diakhiri dengan melakukan pembandingan dan evaluasi tentang apakah yang ada saat ini telah sesuai dengan yang seharusnya dilakukan. Pendekatan penelitian ini menggunakan model penelitian eksplorasi (exploratory research) Hasilnya dipergunakan untuk menyusun model aplikasi Knowledge E-learning di bidang Lingkungan Hidup ini.

Tahap kedua adalah melakukan analisa tentang Knowledge Goal, dan akan diuraikan kedalam proses inti dari pengelolaan pengetahuan (Core Process of KM), yang terdiri dari: knowledge identification, knowledge aqcuition, knowledge development, knowledge sharing and distribution, knowledge utilization, dan knowledge retention. Hasil analisis digunakan untuk pemetaan fitur aplikasi e-learning, yang akan menjadi dasar dalam membuat rancangan aplikasi e-learning. Metode analisis dan perancangan menggunakan pendekatan berbasis objek (OOAD) yang berisi diagram-diagram UML sehingga lebih mudah dipahami.

Tahap ketiga adalah melakukan evaluasi dan verifikasi hasil uji coba prototype aplikasi $e$ learning akan dilakukan pengukuran dengan menggunakan IT Balanced Scorecard melalui 4 (empat) perspektif, yaitu: (1) Government Contribution; (2) Society Orientation; (3) Operation Excellent; (4) Future Orientation.

Penelitian yang dikerjakan saat ini masih pada tahap awal (tahap pertama) dengan melakukan pengayaan materi, melalui kajian teori dan pustaka yang relevan dengan objek yang diteliti. Kajian teori ini akan meningkatkan bobot ilmiah dari content yang nantinya dimuat pada aplikasi $e$-learning tersebut.

\section{HASIL DAN PEMBAHASAN}

\section{Perkembangan Pendidikan Lingkungan Hidup di Tingkat Internasional}

Pada tahun 1975, dalam situs www.menlh.go.id, sebuah lokakarya internasional tentang pendidikan lingkungan hidup diadakan di Beograd, Jugoslavia. Pada pertemuan tersebut dihasilkan pernyataan antar negara peserta mengenai pendidikan lingkungan hidup yang dikenal sebagai "The Belgrade Charter - a Global Framework for Environmental Education". Secara ringkas tujuan pendidikan lingkungan hidup yang dirumuskan dalam Belgrade Charter tersebut di atas adalah sbb: (1) meningkatkan kesadaran dan perhatian terhadap keterkaitan bidang ekonomi, sosial, politik serta ekologi, baik di daerah perkotaan maupun pedesaan; (2) memberi kesempatan bagi setiap orang untuk mendapatkan pengetahuan, keterampilan, sikap, motivasi dan komitmen, yang diperlukan untuk bekerja secara individu dan kolektif untuk menyelesaikan masalah lingkungan saat ini dan mencegah munculnya masalah baru; (3) menciptakan satu kesatuan pola tingkah laku baru bagi individu, kelompok-kelompok dan masyarakat terhadap lingkungan hidup.

Beberapa manfaat atau keuntungan penggunaan e-learning di antaranya adalah menghemat waktu proses belajar mengajar, mengurangi biaya perjalanan dan menghemat biaya pendidikan secara keseluruhan (infrastruktur, peralatan, buku), menjangkau wilayah geografis yang lebih luas, dan melatih peserta lebih mandiri dalam mendapatkan ilmu pengetahuan. 


\section{Perkembangan Pendidikan Lingkungan Hidup di Indonesia}

Memorandum Bersama antara Departemen Pendidikan dan Kebudayaan dengan Kantor Menteri Negara Lingkungan Hidup No. 0142/U/1996 dan No Kep: 89/MENLH/5/1996 tentang Pembinaan dan Pengembangan Pendidikan Lingkungan Hidup, tanggal 21 Mei 1996. Sejalan dengan itu, Direktorat Jenderal Pendidikan Dasar dan Menengah (Dikdasmen) Departemen P \& K juga terus mendorong pengembangan dan pemantapan pelaksanaan pendidikan lingkungan hidup di sekolahsekolah antara lain melalui penataran guru, penggalakkan bulan bakti lingkungan, penyiapan Buku Pedoman Pelaksanaan Pendidikan Kependudukan dan Lingkungan Hidup (PKLH) untuk Guru SD, SLTP, SMU dan SMK , program sekolah asri, dan lain-lain. Selain itu, berbagai insiatif dilakukan baik oleh pemerintah, LSM, maupun erguruan tinggi dalam mengembangkan pendidikan lingkungan hidup melalui kegiatan seminar, sararasehan, lokakarya, penataran guru, pengembangan sarana pendidikan seperti penyusunan modul-modul integrasi, buku bacaan dan lainya.

\section{Perkembangan dan Teknologi E-Learning Systems}

Seiring dengan perkembangan Teknologi Informasi, kebutuhan akan suatu konsep dan mekanisme belajar mengajar berbasis TI menjadi penting. Konsep yang dikenal sebagai e-learning ini membawa pengaruh terjadinya proses perubahan model pendidikan ke bentuk digital, baik isi (contents) dan sistemnya. Menurut Horton(2009) pada Gambar 1, model belajar berbasis IT khususnya e-learning, perlu dua aspek yaitu aspek perangkat dan aspek content. Aspek perangkat - sebagai sebuah perangkat belajar, e-learning dibedakan kedalam tiga komponen yaitu komponen untuk membuat materi ajar (authoring tools), komponen untuk menyampaikan materi ajar (offering tools), dan komponen untuk mengakses dan menampilkan materi ajar (accessing tools). Ketiga komponen perangkat ini meliputi bagian2 untuk menyiapkan, mengkoversi dan menampilkan materi ajar. Aspek konten - isi materi ajar disebut content, dirangkai seperti halnya dalam proses belajar mengajar pada umumnya, yaitu mulai menyiapkan garis-garis besar pembelajaran, kurikulum, silabus, course, lesson, page dan media. Dalam mengorganisasikan susunan dalam materi pengajaran, harus memperhatikan kemampuan pembelajar(learner) agar penyampaian materi tidak terlalu panjang sehingga menyulitkan bahkan membosankan pagi mereka dalam mengikutinya. Materi ajar dibuat agar menarik, mudah dibaca, sederhana dan ringkas. Salah satu pedoman sederhana seperti dikatakan oleh Rosen (2009), bahwa kecepatan seseorang membaca rata-rata satu slide (page) per menit, sedangkan kemampuan berkonsentrasi seseorang diperkirakan antara 15 sampai 20 menit setiap kali mempelajari sesuatu. Dengan demikian dalam menyusun materi ajar yang besar perlu dibagi-bagi ke dalam kumpulan page atau disebut paragraph, kumpulan topik dan course.

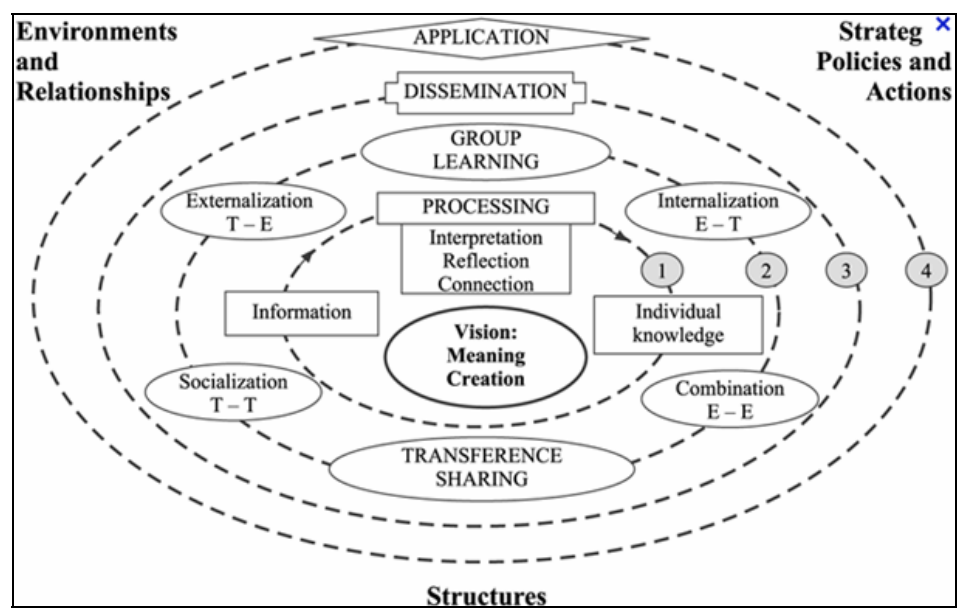

Gambar 1 Model KMS e-learning (Horton, 2009) 


\section{Perlunya E-Learning}

Merujuk pada definisi e-learning secara umum di atas, dapat diartikan bahwa (1) e-learning merupakan suatu jenis belajar mengajar yang memungkinkan tersampaikannya bahan ajar ke siswa dengan menggunakan media internet, intranet atau media jaringan komputer lain (Erdmann, 2004). (2) e-learning adalah sistem pendidikan menggunakan aplikasi elektronik untuk mendukung belajar mengajar dengan media internet, jaringan komputer, maupun komputer standalone (Casal, et al., 2005). E-learning adalah pembelajaran distance Learning yang memanfaatkan teknologi komputer, jaringan komputer Internet. E-learning memungkinkan pembelajar untuk belajar melalui komputer di tempat mereka masing-masing tanpa harus secara fisik pergi mengikuti pelajaran/perkuliahan di kelas.

\section{Model Knowledge E-Learning Lingkungan Hidup}

Interpretasi dari pendidikan berkesinambungan yg menghubungkan antara teori dengan domain afektif yaitu nilai, sikap dan perilaku (Kerry Shephard, 2007) dalam ruang lingkup lingkungan hidup adalah contoh tentang bagaimana teori dan pengalaman yang relevan bisa dikelola untuk pendidikan berkelanjutan. Kesinambungan adalah pemanfaatan potensi lebih dari keunggulan teknologi informasi didalam program lingkungan hidup yang lebih efektif. (Box, 2002). Implikasi teknologi informasi berdampak pada hubungan sosial serta ekonomi informasi yang sangat berguna bagi generasi penerus dalam kerangka kearifan budaya. (Christian Fuchs, 2008).

Kemajuan sistem dan teknologi informasi membawa pengaruh perubahan sosial dan memberikan imbas penting pada kemajuan ekonomis, sosial dan area lingkungan dan selanjutnya akan berimbas pula pada kesinambungan ekonomi social (Casal, et al., 2005), eksplorasi mendalam secara kualitatif dan kemampuan akses kuantitatif dari sistem dan teknologi informasi akan mendorong dan mempengaruhi lingkungan hidup menuju peluang dan tantangan tahu masa depan. (Erdmann et al., 2004).

Penilaian aspek terkait dengan pengembangan berkesinambungan meliputi ketersediaan informasi dan standarisasi lingkungan dari aspek dan kriteria sosial perlu dimasukkan dalam kerangka kerja ('Framework') pengelolaan siklus hidup implementasi sistem pada setiap komunitas. (Brent, 2007). Penggabungan konsep lingkungan hidup, konsep sistem dan konsep teknologi informasi dapat dimanfaatkan untuk mendukung program pelestarian lingkungan hidup termasuk didalamnya adalah aktifitas sosialisasi seperti yang selama ini telah dilakukan dengan baik, walaupun dengan cara searah dari fasilitator ke masyarakat (facilitator centric), belum menempatkan masyarakat/ partisipan sebagai pusat (participant centric).

Model Knowledge e-learning (Gambar 2), pengguna sebagai partisipan akan berperan aktif dan fasilitator menjadi salah satu referensi dari sejumlah referensi yang ada (fasilitator tidak hanya menjadi satu-satunya nara sumber). Penelitian ini akan membangun cara-cara pelestarian lingkungan hidup dengan memanfaatkan teknologi informasi pada aktifitas sosialisasi dengan konsep participant centric.

Pengembangan aplikasi seperti pada model konseptual ini, dimulai dengan rumusan kebutuhan pengelolaan informasi lingkungan, yaitu: (1) melakukan identifikasi pengetahuan potensial yang dikelola ; (2) menyusun model pengelolaan lingkungan berbasis Web; (3) berdasarkan identifikasi kebutuhan informasi lingkungan dan identifikasi kebutuhan perangkat, selanjutnya melakukan pengembangan identifikasi aplikasi KMS yang diperlukan (4) dan akhirnya melakukan menyusun prototipe dari arsitektur aplikasi knowledge e-learning untuk dikembangkan dan diimplementasikan. 


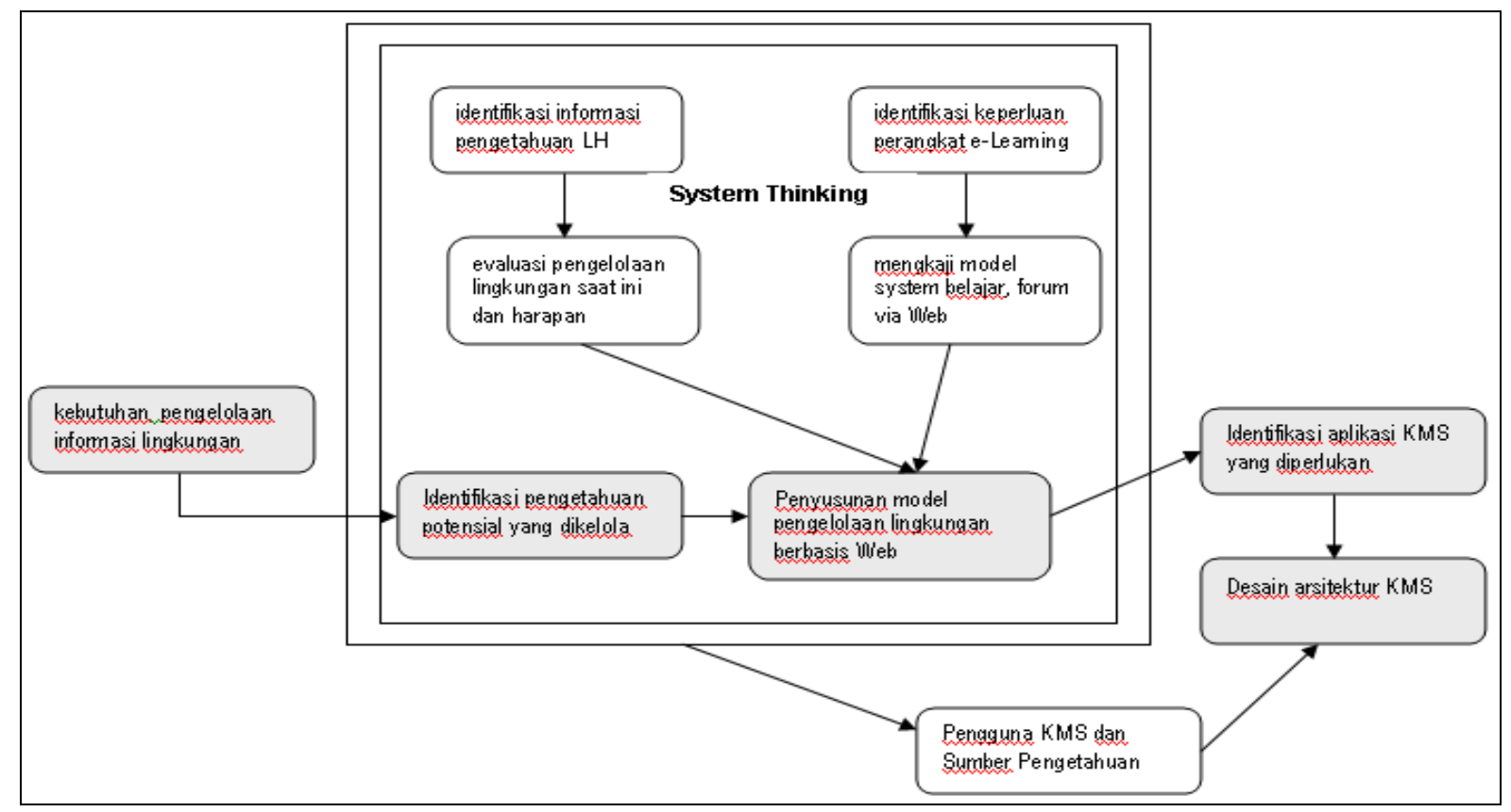

Gambar 2 Model konseptual Knowledge e-Learning (adaptasi dari Hanif Fakhrurroja, 2011)

\section{PENUTUP}

Pemilihan tools untuk pra-penelitian, analisis dan desain aplikasi e-Learning, uji coba sistem, pengembangan contens, dilengkapi indikator keberhasilan sosialisasi mandiri (self assessment). Pembuatan prototype sistem melalui implementasi model yang telah dibuat pada institusi yang terpilih dan membuat rencana pengukuran kinerja secara sistemis serta rancangan penentuan KPI's dan KGI's. Merancang model evaluasi dari perspektif teori, implementasi dan regulasi. Pengambilan data primer dan pengolahan data serta analisis data dengan teknik Factor Analysis dari multivariate statistic yaitu mencari kontribusi positif penggunaan metodologi yang telah dibuat terhadap proses implementasi sistem pada institusi/lembaga/industri dan masyarakat terpilih, yang terjadi karena adanya model sosialisasi yang bisa dilakukan secara mandiri dan terukur.

\section{DAFTAR PUSTAKA}

Amron. (2007). Kajian lingkungan hidup dalam pembangunan wilayah dalam konteks pembangunan infra struktur pekerjaan. Seminar Nasional Pembangunan Wilayah Berbasis Lingkungan di Indonesia, Yogyakarta.

Box, Wesley J. (2002). Sustainability is IT. Pollution Engineering, ABI/INFORM Global.

Brent, Alan C. and Labuschagne, Carin. (2007). An appraisal of social aspects in project and technology life cycle management in the process industry. Management of Environmental Quality: An International Journal, 18 (4), 413-426.

Casal, Carlos R., Van Wunnik, Christine, Sancho, Luis D., Claud, Jean. (2005). How will ICT’s affect our environment in 2020? Foresight: Journal of Futures Studies, Strategic Thinking and Policy; 7 (1), 77. 
Christian Fuchs (2008). The implications of new information and communication technologies for sustainability. Environment, Development and Sustainability, 10 (3), 291.

Erdmann, L., Hilty, L., Goodman, J. and Arnfalk, P. (2004). The future impact of ict's on environmental sustainability. Technical report EUR 21384 EN, IPTS, Seville.

Hanif Fakhrurroja. (2011). Desain arsitektur KMS layanan jasa kalibrasi di UPT LIPI menggunakan soft methodology. Jurnal Teknologi Indonesia, LIP, ISSN: 0126-1533.

Kerry Shephard. (2007). Higher Education for sustainability: Seeking affective learning outcomes. Proquest Journal. 